\title{
Laparoscopic Diagnosis and Treatment of Nonpalpable Testis
}

\author{
Francisco T. Denes, Fernando J. Saito, Frederico A. Silva, Amilcar M. Giron, Marcos Machado, \\ Miguel Srougi
}

Division of Urology, School of Medicine, University of Sao Paulo, USP, Sao Paulo, SP, Brazil

\begin{abstract}
Introduction: Treatment of the cryptorchid testicle is justified due to the increased risk of infertility and malignancy as well as the risk of testicular trauma and psychological stigma on patients and their parents. Approximately $20 \%$ of cryptorchid testicles are nonpalpable. In these cases, the videolaparoscopic technique is a useful alternative method for diagnosis and treatment.

Materials and Methods: We present data concerning 90 patients submitted to diagnostic laparoscopy for impalpable testicles. Forty-six patients (51.1\%) had intra-abdominal gonads. In 25 testicles of 19 patients, we performed a two stage laparoscopic Fowler-Stephens orchiopexy. The other 27 patients underwent primary laparoscopic orchiopexy, in a total of 29 testicles.

Results: We obtained an overall $88 \%$ success rate with the 2 stage Fowler-Stephens approach and only 33\% rate success using one stage Fowler-Stephens surgery with primary vascular ligature. There was no intraoperative complication in our group of patients. In the laparoscopic procedures, the cosmetic aspect is remarkably more favorable as compared to open surgeries. Hospital stay and convalescence were brief.

Conclusions: In pediatric age group, the laparoscopic approach is safe and feasible. Furthermore, the laparoscopic orchiopexy presents excellent results in terms of diagnosis and therapy of the impalpable testis, which is why this technique has been routinely incorporated in our Department.
\end{abstract}

Key words: testis; cryptorchidism; laparoscopy

Int Braz J Urol. 2008; 34: 329-35

\section{INTRODUCTION}

Cryptorchidism is the most common genitourinary anomaly in male children. Its incidence can reach $3 \%$ in full term neonates, rising to $30 \%$ in premature boys (1). The treatment of the cryptorchid testicle is justified by the increased risk of infertility and malignancy, as well as an associated inguinal hernia and the risk of trauma to the ectopic testicle against the pubis. Furthermore, the psychological stigma of a missing testis for the patient, as well as the parents' anxiety are also factors that justifies this type of treatment $(2,3)$.
About $20 \%$ of cryptorchid testicles are nonpalpable. In these cases, the laparoscopic technique is a useful alternative method of diagnosis and treatment. We assessed our data and present our results, including a comparison between the laparoscopic and two stage Fowler-Stephens approaches.

\section{MATERIALS AND METHODS}

Between September 1994 and September 2005, 90 patients were submitted to diagnostic laparoscopy for impalpable testicles. Of these, 34 
(37.8\%) presented with bilateral, while $56(62.2 \%)$ had unilateral impalpable cryptorchidism. The age and the laterality are presented in Table-1.

Preoperatively, all the patients were examined at least by two different examiners at different times, confirming the diagnosis. Another careful physical examination was performed in the operating room, with the patient under anesthesia. When the testicle was palpated on any one of these occasions, the patient was submitted to an open orchiopexy.

Although the preoperative ultrasound for location of the testicle was performed in some patients, with negative results in all, no patient underwent computerized tomography scan or magnetic nuclear resonance imaging for the same purpose.

There was no age limit for the laparoscopic procedure. The procedure was performed under
Table 1 - Age and laterality data.

\begin{tabular}{lc}
\hline Total patients & 90 \\
Age & 11 months - 22 years \\
(mean 6.4 years) \\
Number of testes (total) & 124 \\
Bilateral & 68 \\
Right side only & 20 \\
Left side only & 36 \\
\hline
\end{tabular}

general anesthesia, with orotracheal ventilation and nasogastric and vesical tubes.

The laparoscopic technique (Figure-1) has previously been described (4-6). The laparoscopic findings were similar to those described by Castilho in 1990 (7), and are summarized in Table-2. Surgical

\section{Port Diagram}

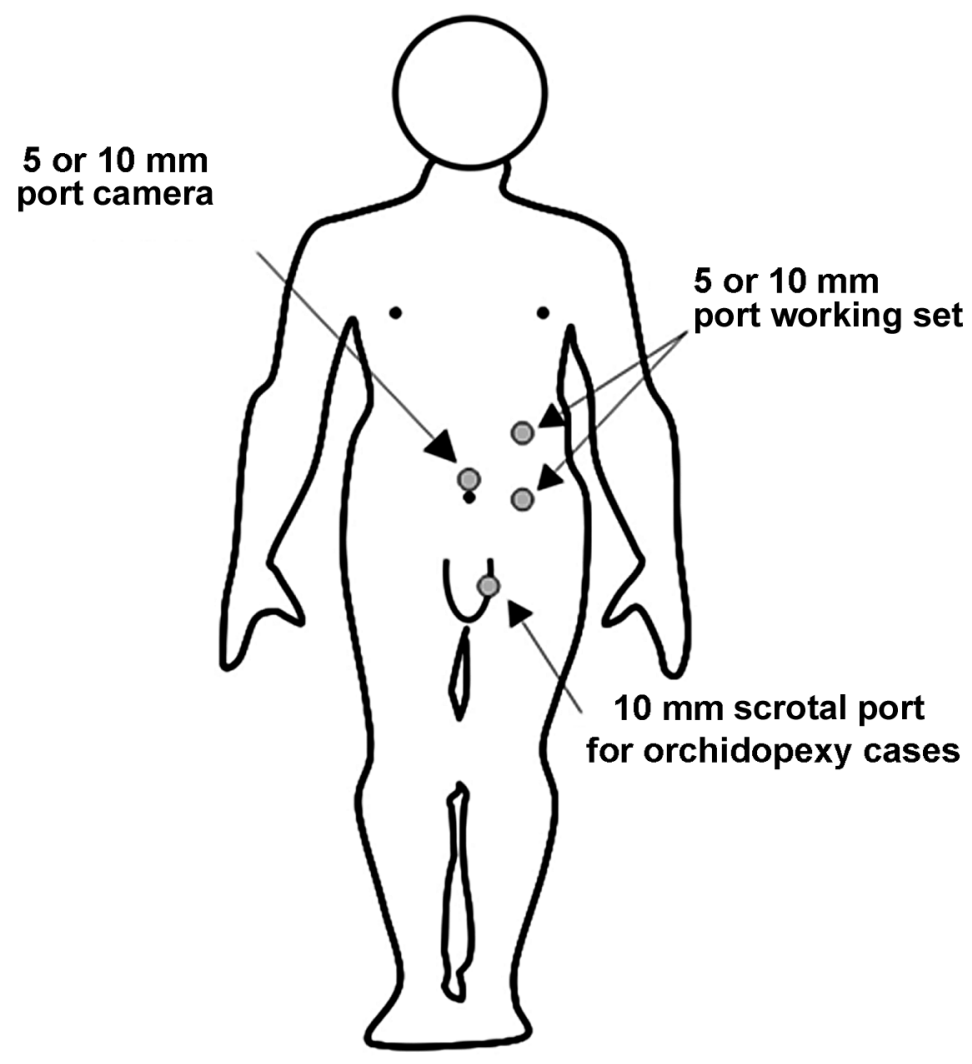

Figure 1 - Surgery diagram for left laparoscopic approach. Note that port diameter varies according to patients'age. 
Table 2 - Laparoscopic findings classification.

\begin{tabular}{ll}
\hline Absent testis & $\begin{array}{l}\text { Agenesis (absence of spermatic vessels and vas deferens). } \\
\text { Vanishing testis (blind ending of spermatic vessels or vas) }\end{array}$ \\
Canalicular testis & $\begin{array}{l}\text { Penetration of vas and spermatic vessels into the internal inguinal ring with or without } \\
\text { directly seeing the testis }\end{array}$ \\
Abdominal testis & $\begin{array}{l}\text { Localized between the inferior renal pole and the ipsilateral internal inguinal ring. Can be } \\
\text { a normal or an atrophic gonad. }\end{array}$ \\
Peeping testis & $\begin{array}{l}\text { Primarily in intra-abdominal position. The testis introduces itself into the inguinal canal due } \\
\text { to the intra-abdominal pressure augmentation during the laparoscopic procedure. Usually } \\
\text { associated with inguinal hernia and returns to its original position by pressing the inguinal } \\
\text { region externally. }\end{array}$ \\
\hline
\end{tabular}

management was performed based on the laparoscopic findings $(8,9)$. In cases of testicle absence , the procedure was interrupted, whereas in cases of intra-canalicular inguinal testis, open surgical exploration was performed. When intra-abdominal testes were found, immediate laparoscopic orchiectomy was performed for atrophic testicles, while patients with viable testicles underwent laparoscopic orchiopexy. The technique of this procedure has been previously described, stressing that in cases of low intra-abdominal testicle (located less than $2 \mathrm{~cm}$ from the internal inguinal ring) the procedure was straightforward, without transection of the spermatic vessels, while in those located higher (more than $2 \mathrm{~cm}$ from the internal inguinal ring) the vessels were sectioned to facilitate the appropriate descent of the testicle to the scrotum (6). When the vessels are transected, the testis is relocated into the scrotum either during the same surgical procedure (primary or one stage Fowler-Stephens) or the relocation is postponed for at least six months after vascular ligature (two stage Fowler-Stephens).

All the operated patients were followed-up for 6 to 100 months, and evaluated for the incidence of intra and post-operative complications, as well as for the final location and morphology of the operated testes. These complications were classified as normal (good size and consistence, in addition to appropriate position in the scrotum), atrophic (altered morphology, independent of the position) or malpositioned (normal morphology, but located above the scrotum).
In cases of unilateral disease, the evaluation of cryptorchid testicle was based on the normal testicle. In cases of bilateral disease, this evaluation was based on clinical palpation as well as ultrasonography in some cases, comparing the obtained values with normal parameters in infancy and adulthood.

\section{RESULTS}

The initial laparoscopic findings are summarized in Table-3. One should note that five patients had bilateral disease, in which we had different diagnostic findings in each affected side as emphasized in Table3.

Eighteen patients (20\%) presented absent testicles, four due to agenesis and 14 to vanishing

Table 3 - Laparoscopic results.

\begin{tabular}{lcc}
\hline Diagnosis & \multicolumn{2}{c}{ Number of Testes } \\
Unilateral & Bilateral \\
\hline Absence & 18 & 8 \\
Canalicular & 17 & 15 \\
Intra-abdominal & 30 & 36 \\
Sub total & 65 & 59 \\
\hline
\end{tabular}

Note: 5 patients had bilateral disease and with different diagnosis for each testis side ( 3 absent and 2 abdominal testicles) 
testes. In these cases, the laparoscopic procedure was completed preventing the patients from any further unnecessary exploration. In 12 patients of this group, who were near pubertal age, a testicular prosthesis was inserted during the same surgical procedure.

Thirty-two patients $(35.5 \%)$ had a diagnosis of intra-canalicular inguinal testicles. In this group, the difficulty in palpating the testis was due to regional obesity, the small size of the testis or general anesthesia, which facilitated the child's examination. The majority of patients underwent a conventional inguinal exploration, and those with viable gonads (34.4\%) had an orchiopexy during the same procedure, while those with atrophic testicles $(65.6 \%)$ underwent orchiectomy. Only one patient underwent a laparoscopic dissection of the inguinal testicle via the internal inguinal ring, where an atrophic testis was found, and removed. In this group, the older children also received testicular prosthesis at the same time. Interestingly, we observed that the presence of a hernia sac almost always indicates the presence of a canalicular testicle, particularly in peeping testis.

In 46 patients $(51.1 \%)$, the testes were intraabdominal, and treatment varied according to their morphology and position (Table-4). In three patients, four testicles were atrophic (one patient with bilateral disease). All were submitted to immediate laparoscopic orchiectomy. In the other 43 patients laparoscopic orchiopexy was performed. In 25 testicles of 19 patients, we performed the two stage laparoscopic Fowler-Stephens orchiopexy, with initial vascular transection. All were submitted to orchiopexy at least six months later. In 21 testicles of 15 patients, the orchiopexy was also done by laparoscopic technique, while the remaining four testicles were positioned by conventional inguinal approach.

The other 27 patients underwent primary laparoscopic orchiopexy, in a total of 29 testicles. In 3 of these testicles ( 3 patients), vascular ligature and section were necessary, while the majority (26 testicles) was relocated to the scrotum with preservation of the vascular pedicle.

Minimal follow-up period was approximately 6 months. Only 2 patients were lost to follow-up during a fifteen year protocol.

Of the 25 testicles advanced into the scrotum by the two step Fowler-Stephens technique, 18 (88\%) presented good morphology and position in the scrotum, while 3 testicles became atrophic. Considering this same group, an $85 \%$ success rate was achieved with the laparoscopic second stage, as compared to a $100 \%$ success rate with the open approach.

Of the 25 testicles submitted to the primary laparoscopic orchiopexy, without vascular transection, $96 \%$ were considered successful, with good position and normal morphology, with only one testis developing atrophy. Among the testes submitted to primary orchiopexy with simultaneous vascular ligature, two presented atrophy, while one testis remained normal (success rate of $33 \%$ ).

There was no intraoperative complication in our group of patients, and none required blood transfusion or conversion to open procedure. All patients who underwent a laparoscopic diagnostic procedure alone

Table 4 - One stage vs. two stage Fowler-Stephens.

\begin{tabular}{llcc}
\hline Two stage surgery* & 2nd Laparoscopic stage & Normal & $18(88 \%)$ \\
& 21 testes & Atrophic & $3(12 \%)$ \\
& 2nd Open stage & Normal & $4(100 \%)$ \\
& 4 testes & Atrophic & 0 \\
One stage surgery** & With vascular ligature & Normal & $1(33 \%)$ \\
& 3 testes & Atrophic & $2(67 \%)$ \\
& Without vascular ligature & Normal & $25(96 \%)$ \\
26 testes & Atrophic & $1(4 \%)$ \\
\hline
\end{tabular}

*19 patients; **27 patients. 
could be fed on the same day and were discharged the following day. Those who underwent orchiopexy were discharged on the second post-operative day. Postoperative pain was minimal and treated with common analgesics or non-steroidal anti-inflammatory drugs, according to patients' age.

In late follow up, we did not observe any post-operative complication in the abdominal or scrotal percutaneous ports, nor inguinal or incisional hernia.

\section{COMMENTS}

The treatment of non-descended testicles is mandatory due to the increased risk of infertility, present in up to $40 \%$ of the patients, as compared to $6 \%$ of control groups (10), including malignancy, which reaches 20 times that of normal adults (11).

Despite the recommendations for the treatment of the cryptorchid testis before 2 years of age, many of our patients were older, due to the socio-economic characteristics of the public health system in our country, the lack of parental information and difficult access to tertiary health care. Although fertility is already compromised in this age group, treatment is necessary not only for the risk of malignancy, but also for the satisfaction and improvement in the quality of the patient's life and parents' concern for their children's health (12).

In relation to diagnosis, some tests can be used for appropriate therapeutic planning. In the case of bilateral impalpable testes, the stimulation with human chorionic gonadotrophin has only a relative usefulness, since a negative result, although suggestive of absent testes, cannot completely exclude the presence of a dysplasic gonad. Even in the case of a positive answer, it is not possible to establish the number, location and the laterality of the gonad (13). Despite a sensitivity of $70-90 \%$ in the diagnosis of inguinal testes, ultrasonography is not useful in intra-abdominal cases(14). Although presenting a better quality, both computed tomography and nuclear magnetic resonance lack sufficient sensitivity and specificity to be considered as gold standard diagnostic tools (15). More recently, the magnetic angioresonance was introduced with sensibility of $96 \%$ and specificity of
$100 \%$, but it is still a new method, with high costs, also requiring general anesthesia in children (16).

In relation to the treatment, the use of gonadotrophin for undescended testes presents a success rate of definitive descent to the scrotum of 21 to $56 \%$, with better results in bilateral cases $(13,14)$. Surgical treatment via an inguinal incision is the main treatment option for palpable testicles, but can also be employed for the evaluation and treatment of impalpable testis. In this situation, however, surgical exploration can often require large incisions and extensive dissections, especially in bilateral cases. This can be avoided using laparoscopic evaluation, with a sensitivity and specificity reaching more than $90 \%(17,18)$.

In $20 \%$ of our patients with testicular agenesis or vanishing testis, laparoscopic surgery was the decisive diagnostic method and saved these patients from any further incision or unnecessary investigation. In patients with intra-canalicular testicles, laparoscopy was fundamental for guiding the minimal inguinal exploration, which was augmented only in cases of a viable gonad, when orchiopexy was performed.

In cases of intra-abdominal testicles, the great advantage of laparoscopy is that, besides correct diagnosis, it enables the therapeutic handling of the testes at the same time. Additionally in cases of associated inguinal hernia (particularly in cases with peeping testis), the laparoscopic approach also enables the simultaneous treatment of the hernia sac with favorable results.

Careful dissection of the spermatic vessels as well as preservation of the peri-deferential vessels are fundamental to ensure testicular preservation. As regards late outcome, we have achieved results comparable to those reported in the literature for laparoscopic orchiopexy, with success rate of $88 \%$ for the staged Fowler-Stephens technique, and 96\% in the primary orchiopexy without vascular transection $(8,17,19)$. One should be aware of the inferior results of the laparoscopic primary orchiopexy with vascular ligature (primary or one stage Fowler-Stephens). In the literature (20), the reported success was $74.1 \%$. In our series, with the exception of a few cases, we only reached $33 \%$ of well located and normal testes. Based on these results, the laparoscopic one stage Fowler-Stephens orchiopexy, with spermatic vessel ligature, has been abandoned in our Department. 
Using laparoscopic procedures, the cosmetic aspect is remarkably more favorable as compared to open surgery, and the hospital stay and convalescence are much shorter. In the pediatric age group, these factors may not be so evident for the patient themselves, but certainly will be for the parents, who are able to resume their daily activities earlier. Furthermore, the laparoscopic orchiopexy presents excellent results in terms of diagnosis and therapy of the impalpable testis, which is why this technique has been routinely incorporated in our Department. It is noteworthy that our preference is the primary orchiopexy without transection of the gonadal vessels. However, in cases of very high testicles or those with short vessels we now recommend the two staged laparoscopic technique of Fowler-Stephens.

\section{CONFLICT OF INTEREST}

None declared.

\section{REFERENCES}

1. Berkowitz GS, Lapinski RH, Dolgin SE, Gazella JG, Bodian CA, Holzman IR: Prevalence and natural history of cryptorchidism. Pediatrics. 1993; 92: 44-9.

2. Trussell JC, Lee PA: The relationship of cryptorchidism to fertility. Curr Urol Rep. 2004; 5: 142-8.

3. Moreno-Garcia M, Miranda EB: Chromosomal anomalies in cryptorchidism and hypospadias. J Urol. 2002; 168: 2170-2; discussion 2172.

4. Poppas DP, Lemack GE, Mininberg DT: Laparoscopic orchiopexy: clinical experience and description of technique. J Urol. 1996; 155: 708-11.

5. Lindgren BW, Franco I, Blick S, Levitt SB, Brock WA, Palmer LS, et al.: Laparoscopic Fowler-Stephens orchiopexy for the high abdominal testis. J Urol. 1999; 162: 990-3; discussion 994.

6. Dénes, FT: Avaliação e tratamento do testículo nãopalpável. In Castilho LN, Laparoscopia Urológica. Campinas, LPC Comunicações, 2000; pp. 467-5.

7. Castilho LN: Laparoscopy for the nonpalpable testis: how to interpret the endoscopic findings. J Urol. 1990; 144: 1215-8.

8. Peters CA, Kavoussi LR, Retik AB: Laparoscopic Management of intra-abdominal testes. J Endourol. 1993; 7(Suppl 1): 170-4.
9. Cortes D, Thorup JM, Lenz K, Beck BL, Nielsen OH: Laparoscopy in 100 consecutive patients with 128 impalpable testes. Br J Urol. 1995; 75: 281-7.

10. Lee PA, O'Leary LA, Songer NJ, Coughlin MT, Bellinger MF, LaPorte RE: Paternity after unilateral cryptorchidism: a controlled study. Pediatrics. 1996; 98: 676-9.

11. Garner MJ, Turner MC, Ghadirian P, Krewski D: Epidemiology of testicular cancer: an overview. Int J Cancer. 2005; 116: 331-9.

12. Kucheria R, Sahai A, Sami TA, Challacombe B, Godbole H, Khan MS, et al.: Laparoscopic management of cryptorchidism in adults. Eur Urol. 2005; 48: 453-7; discussion 457.

13. Rajfer J, Handelsman DJ, Swerdloff RS, Hurwitz R, Kaplan H, Vandergast T, et al.: Hormonal therapy of cryptorchidism. A randomized, double-blind study comparing human chorionic gonadotropin and gonadotropin-releasing hormone. N Engl J Med. 1986; 314: 466-70.

14. Kolon TF, Patel RP, Huff DS: Cryptorchidism: diagnosis, treatment, and long-term prognosis. Urol Clin North Am. 2004; 31: 469-80.

15. Nguyen HT, Coakley F, Hricak H: Cryptorchidism: strategies in detection. Eur Radiol. 1999; 9: 336-43.

16. Eggener SE, Lotan Y, Cheng EY: Magnetic resonance angiography for the nonpalpable testis: a cost and cancer risk analysis. J Urol. 2005; 173: 1745-9; discussion 1749-50.

17. Docimo, SG: The results of surgical therapy for cryptorchidism: a literature review and analisys. J Urol. 1995; 154: 1148-52.

18. Froeling FM, Sorber MJ, de la Rosette JJ, de Vries JD: The nonpalpable testis and the changing role of laparoscopy. Urology. 1994; 43: 222-7.

19. Lindgren BW, Darby EC, Faiella L, Brock WA, Reda EF, Levitt SB, et al.: Laparoscopic orchiopexy: procedure of choice for the nonpalpable testis? J Urol. 1998; 159: 2132-5.

20. Baker LA, Docimo SG, Surer I, Peters C, Cisek L, Diamond DA, et al.: A multi-institutional analysis of laparoscopic orchidopexy. BJU Int. 2001; 87: 484-9.

$\overline{\text { Accepted after revision: }}$

October 20, 2007

Correspondence address:

Dr. Francisco Tibor Dénes

Rua Barata Ribeiro, 414, Conjunto 34/35

São Paulo, SP, 01308-080, Brazil

E-mail: ftdenes@terra.com.br 


\section{EDITORIAL COMMENT}

Laparoscopy is an accepted diagnostic and treatment modality for non-palpable testes as performed in the current series. In this series, the percentage of intra-canalicular viable testis which was not palpable during the examination even under anesthesia is high (34.4\% of 32 patients) and it is not similar to our experience (1). Whatever the reason, we encourage the authors to perform laparoscopic orchiopexy instead of converting the operation to open surgery in this situation.

Classification of intra-abdominal testes according to the measurement of distance between the testes and the internal inguinal ring is a good criterion but in our series, we have few cases, which do not match this criterion. Based on these observations, we prefer to examine the mobility of the testis by a laparoscopic forceps and to decide if the length of the spermatic vessels and ductus deferens is suitable for one or two stage operation.

In our series, a few cases were previously explored by open or laparoscopic technique at another center and, diagnosed as "absence of testis". In those cases, we had documented positive response to HCG stimulation test and diagnostic laparoscopy revealed the presence of an intra-abdominal testis. Therefore, we advocate performing an HCG stimulation test in patients with bilateral non-palpable testes before surgical exploration.

The authors performed testicular prosthesis placement following laparoscopic exploration in older patients with vanishing testis. We recommend a similar option for the younger patients and, this alternative approach could be offered to the parents before laparoscopic exploration. Inguinal exploration may be postponed and, testicular nubbins can be removed later at the time of testicular prosthesis implantation surgery if there is a consensus with the family (2).

\section{REFERENCES}

1. Topuzlu Tekant G, Emir H, Eroðlu E, Akman M, Büyükünal C, Danipmend N, et al.: Experience with laparoscopy in nonpalpable testis. Eur J Pediatr Surg. 2001; 11: 177-81.

2. Emir H, Ayik B, Eliçevik M, Büyükünal C, Danipmend N, Dervipoðlu S, et al.: Histological evaluation of the testicular nubbins in patients with nonpalpable testis: assessment of etiology and surgical approach. Pediatr Surg Int. 2007; 23: 41-4.

Dr. Haluk Emir Division of Pediatric Urology Cerrahpaşa Medical Faculty Istanbul University Istanbul, Turkey E-mail:hemir@istanbul.edu.tr 